\title{
Corrosion Studies of Zinc Coated Steel Parts in Sea Water
}

\author{
S. Karthikeyan and P.A. Jeeva* \\ Centre for Innovative Manufacturing Research, VIT University, Vellore, India
}

Received January 19, 2017; accepted September 20, 2018

\begin{abstract}
The corrosion inhibition of zinc coated steel sheets immersed in $3.5 \% \mathrm{NaCl}$ with sulfisoxazole (SSZ) has been reported by weight loss, potentiodynamic polarization, electrochemical impedance spectroscopy, hydrogen permeation studies and quantum mechanical studies. All these techniques indicate that SSZ significantly inhibits zinc coated steel corrosion in a $3.5 \% \mathrm{NaCl}$ medium. Polarization studies confirmed that the inhibition mode follows a mixed type. The adsorption of the compounds onto the zinc coated steel surface obeyed Langmuir adsorption isotherm.
\end{abstract}

Keywords: antibiotics, hydrogen permeation, corrosion inhibitors, non-toxic.

\section{Introduction}

Zinc coated steel is widely used in applications such as buildings, automotive metal parts and water pipeline systems, because of its excellent corrosion resistance to moisture [1-6]. However, failure of zinc coated pipes and tanks has been reported to be due to corrosion processes in chloride environments, which is evident from the formation of rust in those systems, leading to severe damage of industrial components. [7].

Numerous reports on zinc coated steel corrosion resistance to acidic media are available, but the use of inhibitors is an important one [8-10].

The usage of inhibitors is inexpensive and a real method to reduce electrochemical corrosion. Numerous organic compounds which have $\pi$ bonds and contain hetero atoms were reported as corrosion inhibitors by several investigators [11-16], for the dissolution of iron in acidic media. Research findings in recent times have focused on emerging cheap, non-toxic drugs as environment responsive corrosion inhibitors [17-24].

Literature review indicates that few antibiotics have been reported as corrosion inhibitors for steel and aluminum corrosion in acidic and alkaline media [25]. Very recently, Hari Kumar et al. [26] used ampicillin drug as an inhibitor for mild steel corrosion in $1 \mathrm{M} \mathrm{HCl}$. Nevertheless, as no concrete results have been published for the corrosion inhibition of zinc steel sheet in $5 \% \mathrm{NaCl}$ with the use of sulfisoxazole (SSZ) as inhibitor, the present study has researched this method.

\footnotetext{
* Corresponding author. E-mail address: p.a.jeeva@gmail.com
} 
The inhibition efficiencies of the compound were calculated using mass loss and electrochemical techniques. Rarely, the usage of hydrogen permeation measurement studies for this green inhibitor established the prominent performance of the inhibitors. This inhibitor is strong enough, amply planar and is able to block more galvanized steel surface areas.

\section{Materials and methods}

\section{Materials}

Zinc sheet specimens of size $1 \times 4 \mathrm{~cm}^{2}$ were used for mass loss and electrochemical studies. The aggressive solution of $3.5 \% \mathrm{NaCl}$ [AR grade] was used for all the studies. The antibiotic namely sulfisoxazole was procured from Sigma Aldrich. The structure of the green inhibitor is given in Fig. 1, which also includes 13 C-NMR shifts. Electrochemical experiments were performed with a three electrode cell assembly with zinc samples as working electrode, platinum as counter electrode and saturated calomel [SCE] as reference electrode.

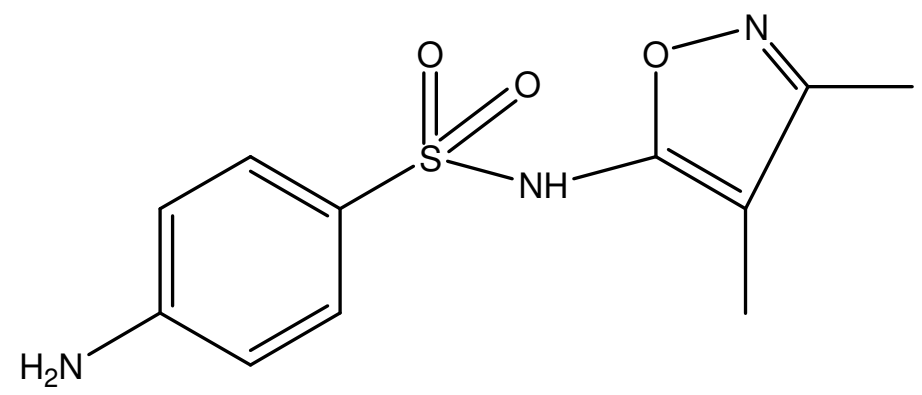

Figure 1. Structure of sulfisoxazole.

\section{Mass loss studies}

Mass loss and hydrogen permeation studies were done as described earlier [27]. The inhibitor concentrations used for weight loss and electrochemical studies were from $10 \mathrm{ppm}$ to $100 \mathrm{ppm}$. Zinc metal specimens of size $1 \times 4 \mathrm{~cm}^{2}$ were abraded with different emery papers, and then degreased with acetone. The cleaned surfaces were washed with double distilled water, air dried and preserved in the desiccator. The mass loss study was followed at room temperature for three hours in $5 \% \mathrm{NaCl}$. The inhibition efficiency (IE\%) according to mass loss was calculated by the following equation:

$$
\text { Inhibition efficiency }(\mathrm{IE} \%)=\left(W_{a}-W_{\mathrm{p}} / W_{a}\right) \times 100(1)
$$

where $\mathrm{W}_{\mathrm{a}}$ and $\mathrm{W}_{\mathrm{p}}$ are the weight loss values in the absence and presence of the green inhibitor.

\section{Potential-current measurements by electrochemical studies}

Potentiodynamic polarization measurements were monitored in a conventional three electrode cylindrical glass cell, using $\mathrm{CH}$ electrochemical analyser at a scan rate of $5 \mathrm{mV} \mathrm{s}^{-1}$. Before carrying out the polarization measurements, the solution 
was deaerated for $20 \mathrm{~min}$, and the working electrode was maintained at its corrosion potential for 20 min, until a steady state was obtained. The zinc surface was immersed into various inhibitors concentrations in $100 \mathrm{~mL}$ of $5 \% \mathrm{NaCl}$, at room temperature. The inhibition efficiency (IE\%) was calculated using the following equation:

$$
\text { Inhibition efficiency }(\mathrm{IE} \%)=\left(I_{\mathrm{a}}-I_{\mathrm{p}} / I_{\mathrm{a}}\right) \times 100
$$

where $I_{a}$ and $I_{p}$ are the corrosion current densities without and with the green inhibitor, respectively.

The potentiodynamic current-potential curves were recorded by automatically changing the electrode potential from $-950 \mathrm{mV}$ to $+100 \mathrm{mV}$ versus the open circuit potential. The corresponding corrosion current $\left(\mathrm{I}_{\text {corr }}\right)$ was recorded. Tafel plots were made by plotting $E$ versus $\log I$. Corrosion potential $\left(\mathrm{E}_{\mathrm{corr}}\right)$, corrosion current density ( $\left.\mathrm{I}_{\text {corr }}\right)$ and cathodic and anodic slopes $\left(\beta_{\mathrm{c}}\right.$ and $\left.\beta_{\mathrm{a}}\right)$ were calculated according to known procedures.

Impedance measurements were done in the frequency range from 0.1 to 10000 $\mathrm{Hz}$, by means of amplitude of $20 \mathrm{mV}$ and $10 \mathrm{mV}$ peak to peak, with an AC signal at open-circuit potential. Charge transfer resistance $\left(\mathrm{R}_{\mathrm{ct}}\right)$ and double layer capacitance $\left(\mathrm{C}_{\mathrm{dl}}\right)$ values were obtained from the Nyquist plot [28-30]. The percentage inhibition efficiency was calculated from the following equation:

$$
\text { Inhibition efficiency }(\mathrm{IE} \%)=\left(C_{\mathrm{dl}}^{\mathrm{a}}-C_{\mathrm{dl}}^{\mathrm{p}} / C_{\mathrm{dl}}^{\mathrm{a}}\right) \times 100
$$

where $\mathrm{C}_{\mathrm{dl}^{\mathrm{a}}}{ }^{\mathrm{a}}$ and $\mathrm{C}_{\mathrm{dl}}^{\mathrm{p}}$ are the charge transfer resistance of zinc sheets, without and with green inhibitor, respectively.

\section{Results and discussion}

\section{Mass loss studies}

The values of inhibition efficiency (IE\%) and surface coverage $(\theta)$ calculated for the green inhibitor at different concentrations, for the corrosion reaction of zinc sheets in $3.5 \% \mathrm{NaCl}$ from the mass loss data, are summarized in Table 1. It was established that the inhibition efficiency increased with higher inhibitor concentrations. It was also ostensible that the corrosion rate decreased higher with green inhibitor concentrations. It was clear that the inhibitors retarded the zinc sheet corrosion at all the concentrations used in the study. Maximum inhibition efficiency was observed at $100 \mathrm{ppm}$ concentrations of sulfisoxazole.

\section{Potential-current measurements by electrochemical studies}

Polarization results, such as the values of corrosion potential $\left(\mathrm{E}_{\mathrm{corr}}\right)$, corrosion current densities $\left(I_{c o r r}\right)$, anodic Tafel slope $\left(\beta_{\mathrm{a}}\right)$, cathodic Tafel slope $\left(\beta_{\mathrm{c}}\right)$, surface coverage $(\theta)$ and inhibition efficiency (IE\%), were calculated using polarization curves for the corrosion of zinc sheets in $3.5 \% \mathrm{NaCl}$, and are summarized in Table 2 . It can also be seen from the table that the corrosion current ( $\left.\mathrm{I}_{\text {corr }}\right)$ value 
declines with an increase in the green inhibitor concentration. Further, it was established that increasing concentrations of sulfisoxazole enhanced the values of both $\beta_{\mathrm{a}}$ and $\beta_{\mathrm{c}}$, in a random manner.

Hence, corrosion inhibition by this compound was under cathodic control, but chiefly under mixed type. The inhibition efficiency (IE\%) and surface coverage $(\theta)$ increased with higher SSZ dosages in the experiment. The maximum inhibition efficiency was obtainable at a concentration of $100 \mathrm{ppm}$. A definite relationship exists between the results obtained from mass loss and potentialcurrent studies for the above inhibitor.

Table 1. Values of inhibition efficiency and surface coverage for the dissolution of zinc in $3.5 \% \mathrm{NaCl}$, in the presence of different concentrations of sulfisoxazole, obtained from mass loss measurements.

\begin{tabular}{|c|c|c|}
\hline $\begin{array}{c}\text { Inhibitor concentrations } \\
(\mathrm{ppm})\end{array}$ & $\begin{array}{c}\text { Inhibitor efficiency (IE) } \\
(\%)\end{array}$ & $\begin{array}{c}\text { Surface coverage } \\
(\theta)\end{array}$ \\
\hline Sulfisoxazole & & - \\
\hline Blank & - & 0.75 \\
\hline $30 \mathrm{ppm}$ & 75.42 & 0.88 \\
\hline $70 \mathrm{ppm}$ & 87.87 & 0.98 \\
\hline $100 \mathrm{ppm}$ & 98.32 & \\
\hline
\end{tabular}

Table 2. Electro kinetic parameters and inhibition efficiency for zinc corrosion in $3.5 \%$ $\mathrm{NaCl}$, obtained by the polarization method in sulfisoxazole presence.

\begin{tabular}{|c|c|c|c|c|c|c|}
\hline $\begin{array}{c}\text { Inhib. conc. } \\
(\mathrm{ppm})\end{array}$ & $\begin{array}{c}E_{\text {corr }} \\
(\mathrm{mV} \text { vs. SCE })\end{array}$ & $\begin{array}{c}I_{\text {corr }} \\
\left(\mu \mathrm{A} \mathrm{cm}^{-2}\right)\end{array}$ & $\begin{array}{c}\beta \mathrm{a} \\
\left(\mathrm{mV} \mathrm{dec}^{-1}\right)\end{array}$ & $\begin{array}{c}\beta \mathrm{c} \\
\left(\mathrm{mV} \mathrm{dec}^{-1}\right)\end{array}$ & $\begin{array}{c}I E \\
(\%)\end{array}$ & $\theta$ \\
\hline Blank & -856.68 & 645.15 & 100.2 & 150.5 & - & - \\
\hline Sulfisoxazole & & & & & & \\
\hline 30 & -832.25 & 159.79 & 81.5 & 128.2 & 75.01 & 0.75 \\
\hline 70 & -800.52 & 76.87 & 97.4 & 134.4 & 87.97 & 0.88 \\
\hline 100 & -791.69 & 10.43 & 74.2 & 101.2 & 98.34 & 0.98 \\
\hline
\end{tabular}

\section{Electrochemical impedance studies}

The Nyquist representations of zinc's impedance behaviour in $3.5 \% \mathrm{NaCl}$, with and without the addition of various inhibitors concentrations, are given in Table 3.

Table 3. Electrochemical impedance parameters for the dissolution of the zinc sheet rod in $5 \% \mathrm{NaCl}$, with and without the SSZ compound.

\begin{tabular}{|c|c|c|c|c|}
\hline $\begin{array}{c}\text { Inhibitor conc. } \\
(\mathrm{ppm})\end{array}$ & $\begin{array}{c}R_{\mathrm{ct}} \\
\left(\Omega \mathrm{cm}^{2}\right)\end{array}$ & $\begin{array}{c}C_{\mathrm{dl}} \\
\left(\mathrm{F} \mathrm{cm}^{-2}\right)\end{array}$ & $\begin{array}{c}I E \\
(\%)\end{array}$ & $\begin{array}{c}\text { Surface coverage } \\
(\theta)\end{array}$ \\
\hline Blank & 47.2 & 0.296 & - & - \\
\hline Sulfisoxazole & & & & 0.75 \\
\hline 30 & 127.35 & 0.0734 & 75.07 & 0.87 \\
\hline 70 & 189.42 & 0.0381 & 86.78 & 0.98 \\
\hline 100 & 280.73 & 0.0048 & 98.35 & \\
\hline
\end{tabular}

The table also contains the values of charge transfer resistance $\left(\mathrm{R}_{\mathrm{ct}}\right)$ and double layer capacitance $\left(\mathrm{C}_{\mathrm{dl}}\right)$ derived from Nyquist plots, for the dissolution of zinc in 
sea water. $R_{c t}$ values were seen to increase with higher concentrations of the green compound in sea water.

It was found that $\mathrm{C}_{\mathrm{dl}}$ values were brought down by enhancing sulfisoxazole concentrations in the sea water medium. This can be accredited to the increasing adsorption of the inhibitor onto the metal surface with higher concentrations [33].

\section{Adsorption isotherm}

The degree of surface coverage $(\theta)$ for different sulfisoxazole concentrations in $5 \% \mathrm{NaCl}$ has been calculated from weight loss, polarization and electrochemical impedance studies. The obtained data were graphically tested for fitting the suitable isotherm [34-36]. A straight line was observed by plotting log $(\mathrm{C} / \theta) \mathrm{vs}$. $\log \mathrm{C}$, which ratifies that the adsorption of this green inhibitor observed Langmuir adsorption isotherm.

The Langmuir isotherm for the adsorbed layers is given by the following equation [37]:

$$
C_{\mathrm{inh}} / \theta=1 / K_{\mathrm{ads}}+C_{\mathrm{inh}}
$$

where $\mathrm{K}_{\mathrm{ads}}$ is the equilibrium constant of the adsorption/desorption process. The adsorption equilibrium constant $\left(\mathrm{K}_{\mathrm{ads}}\right)$ and free energy of adsorption $\left[\Delta G_{\mathrm{ads}}^{\mathrm{o}}\right]$ were calculated using the following equations [38]:

$$
\begin{aligned}
& K_{\mathrm{ads}}=1 / C_{\mathrm{inh}} \times \theta / 1-\theta \\
& \Delta G_{\mathrm{ads}}^{\mathrm{o}}=-2.303 R T \log \left[55.5 K_{\mathrm{ads}}\right]
\end{aligned}
$$

where 55.5 is the molar concentration of water in the solution [38-39], $\mathrm{R}$ is the gas constant and $\mathrm{T}$ is the temperature. The values of the adsorption equilibrium constant $\left(\mathrm{K}_{\mathrm{ads}}\right)$ and free energy of adsorption $\left(\Delta \mathrm{G}_{\text {ads }}^{\mathrm{o}}\right)$ are given in Table 4 . The negative values of $\Delta \mathrm{G}^{0}$ ads showed that the adsorption of sulfisoxazole onto the zinc surface in a chloride environment was a spontaneous process. It is wellknown that $\Delta \mathrm{G}_{\text {ads }}^{\mathrm{o}}$ values of $20 \mathrm{kJmol}^{-1}$ or lower indicate physisorption, while those of $-40 \mathrm{kJmol}^{-1}$ or higher involve charge sharing or transfer from the inhibitors to the metal surface, to form a co-ordinate bond, of which process is known as chemisorption. The values of the free energy of adsorption $\left(\Delta \mathrm{G}^{\mathrm{o}}\right.$ ads $)$ in this study ranged from -28 to $-32 \mathrm{kJmol}^{-1}$, demonstrating that the adsorption was not just a physisorption process, as it may include some other interactions [4043].

Table 4. Gibbs free energy parameters and adsorption equilibrium constant $\left(\mathrm{K}_{\mathrm{ads}}\right)$ of the green inhibitor (SSZ), at different temperatures, evaluated by mass loss method.

\begin{tabular}{|c|c|c|}
\hline $\begin{array}{c}\text { Temperature } \\
{[\mathrm{K}]}\end{array}$ & $\begin{array}{c}K_{\text {ads }} \\
\text { Green inhibitor }\end{array}$ & $\begin{array}{c}-\Delta G_{\text {ads }}^{\mathrm{o}} \\
{\left[\mathrm{kJmol}^{-1}\right]}\end{array}$ \\
\hline 313 & 931 & 28.33 \\
\hline 323 & 1164 & 29.82 \\
\hline 333 & 1341 & 31.17 \\
\hline
\end{tabular}




\section{Mechanism of inhibition}

In sulfisoxazole, the presence of lone pairs of electrons of nitrogen and sulfur atoms of both benzamino and sulfoxide groups, along with an oxygen atom, favours the adsorption of sulfisoxazole onto oxidized zinc surfaces, by virtue of donating electrons to the positively charged $\mathrm{Fe}$ atoms, when exposed to a chloride environment.

\section{Quantum mechanical studies}

Quantum mechanical calculations were carried out to explore the adsorption and inhibition mechanisms of the SSZ compound on the corrosion of galvanized steel surfaces in 5\% NaCl. Figs. 2 and 3 indicate HOMO and LUMO structure of sulfisoxazole. The values of calculated quantum chemical parameters, i.e., Еномо (highest occupied molecular orbital), ELUMo (lowest unoccupied molecular orbital), $\Delta \mathrm{E}$ (energy gap), $\mu$ (dipole moment), etc., are presented in Table 5. Еномо is related to the electron-releasing capability of the inhibitor molecule, while $E_{\text {LUMo }}$ is associated to electrons with the drawing capacity of the inhibitor molecule. In the present investigation, donor-acceptor interactions between the $\pi$ electrons of nitrogen and sulphur atoms of benzamino and sulfoxide groups favoured the effective adsorption of SSZ onto zinc surfaces, which is evidenced from the dense electrons clouds in HOMO and LUMO structure, which are similar in both orbitals. It is well understood that if both HOMO and LUMO structures resemble each other, the resultant inhibitor adsorption will be better onto the metal surface. The gap between HOMO-LUMO energy levels of molecules was another important factor that needed to be considered. The higher is $\Delta \mathrm{E}$ value of an inhibitor, the higher is its inhibition efficiency. It has been reported that large values of the dipole moment will improve corrosion inhibition. Based on the values of $\Delta \mathrm{E}$ and dipole moment, the SSZ compound has been strongly adsorbed onto the galvanized steel surface immersed in $5 \% \mathrm{NaCl}$.

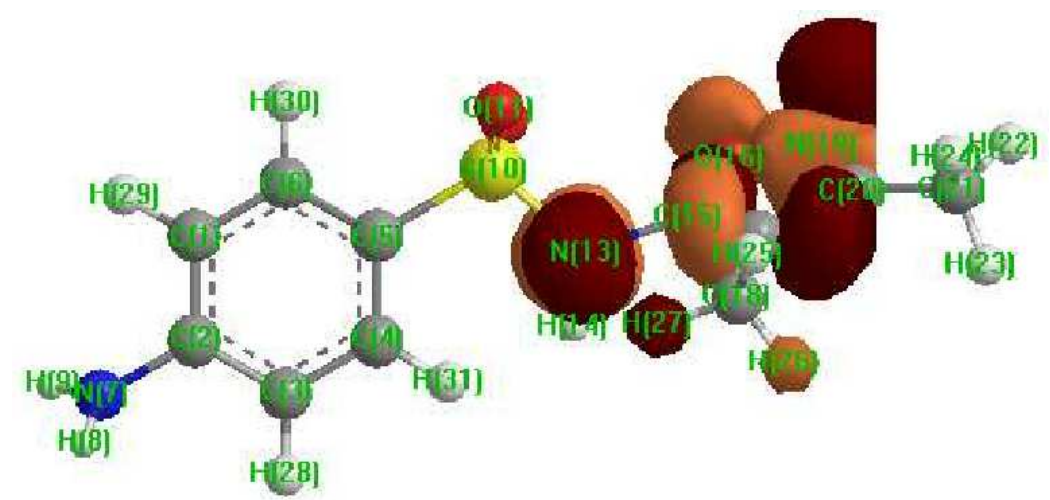

Figure 2. Highest molecular orbital of SSZ molecules during its adsorption onto zinc surfaces. 
Table 5. Quantum mechanical parameters for sulfisoxazole for the corrosion of zinc surfaces.

\begin{tabular}{|c|c|c|c|c|}
\hline Inhibitor & $\begin{array}{c}\text { LUMO } \\
(\mathrm{eV})\end{array}$ & HOMO $(\mathrm{eV})$ & $\Delta \mathrm{E}\left(\mathrm{cal}^{\mathrm{mol}}{ }^{-1}\right)$ & $\begin{array}{c}\text { Dipole moment } \\
(\text { Debye })\end{array}$ \\
\hline Sulfisoxazole (SSZ) & -0.6023 & -8.1775 & 7.5752 & 3.8 \\
\hline
\end{tabular}

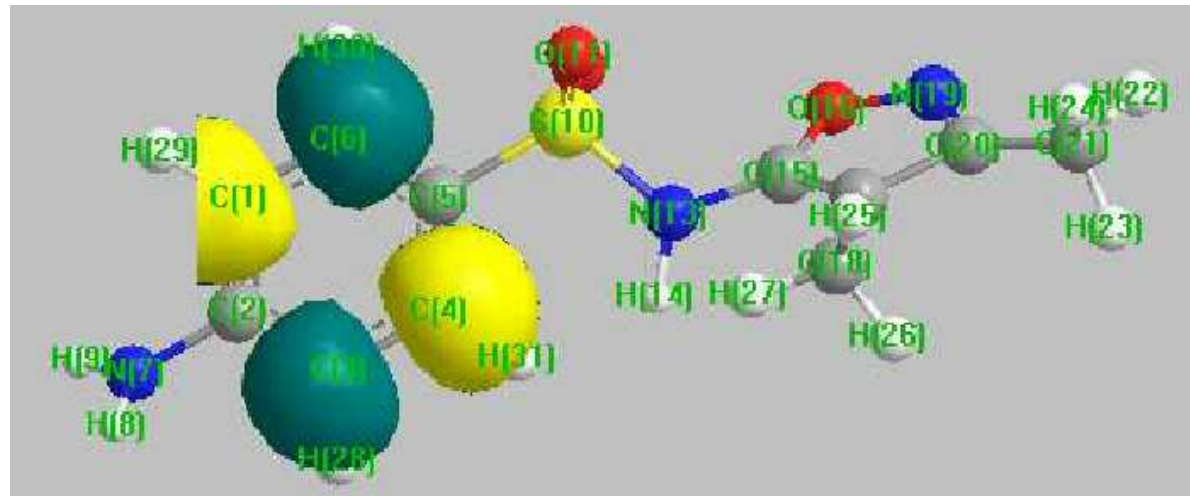

Figure 3. Lowest unoccupied molecular orbital of SSZ molecules during its adsorption onto zinc surfaces.

\section{Conclusion}

The controlled dissolution of zinc surfaces was monitored in $3.5 \% \mathrm{NaCl}$ solutions at different temperatures (313-333 K), without and with various concentrations of sulfisoxazole, a green inhibitor, by adapting chemical and electrochemical methods. The main conclusions are:

1. Sulfisoxazole effectively exhibited inhibiting properties for galvanized steel corrosion in $3.5 \% \mathrm{NaCl}$;

2. Tafel polarization plots designated that the present inhibitor showed a mixed mode of inhibition;

3. the rates of corrosion obtained from the impedance measurements were in good agreement with those recorded using potentiodynamic polarization. This confirms the validity of the corrosion rates measured by the potentiodynamic polarization;

4. the adsorption of sulfisoxazole on zinc surfaces obeyed Langmuir isotherm;

5. apparent activation energies in the presence of sulfisoxazole for the corrosion of zinc in chloride media ranged from 28 to $-32 \mathrm{kJmol}^{-1}$, demonstrating that the adsorption was not just physisorption;

6. quantum mechanical results confirmed the remarkable performance of SSZ inhibitor through its real adsorption onto zinc surfaces exposed to $3.5 \% \mathrm{NaCl}$.

\section{References}

1. Sherif, El-Sayed M, Almajid AA, Bairamov AK, et al. Int J Electrochem Sci. 2012;7:2796.

2. Yadav AP, Katayama H, Noda K, et al. Electrochim Acta. 2007;52:3121.

3. Amin MA, El Rehim SSA, Moussa SO, et al. Electrochim Acta. 2008;53:5644-5652. 
4. Lin B-L, Lu J-T, Kong G. Corrosion Sci. 2008;50:962.

5. Bajat JB, Stanković S, Jokić BM, et al. Surf Coat Tech. 2010;204:2745.

6. Kartsonakis IA, Balaskas AC, Koumoulos EP, et al. Corrosion Sci. 2012;57:30.

7. Zhang XG. Corrosion of zinc and zinc alloys, Corrosion: Materials. ASM Handbook. 2005; p. 402.

8. Liang C, Wang P, Wu B, et al. J Solid State Electrochem. 2010;14:1391.

9. Shukla SK, Quraishi MA. Mater Chem Phys. 2010;120:142.

10. Eddy NO, Ebenso EE. Afri J Pure Appl Chem. 2008;2:1.

11. Singh A, Ahamed I, Singh VK, et al. J Solid State Electrochem. 2011;15:1087.

12. Quraishi MA, Khan S. J Appl Electrochem. 2006;36:539.

13. Khaled KF, Hamed MNH, Abdel-Azim KM, et al. J Solid State Electrochem. 2011;15:663.

14. Hasanov R, Sadikoglu M, Bilgic S. Appl Surf Sci. 2007;253:3913.

15. Umoren SA, Ying Li, Wang FH. J Solid State Electrochem. 2010;14:2293.

16. Bouklah M, Hammouti B, Lagrenee M, et al. Corrosion Sci. 2006;48:2831.

17. Abdallah M. Corrosion Sci. 2002;44:717.

18. Abdallah M. Corrosion Sci. 2004;46:1981.

19. El-Naggar MM. Corrosion Sci. 2004;49:2226.

20. Solmaz R, Kardas G, Yazici B, et al. Protection Metals. 2005;41:581.

21. Xavier JR, Nallaiyan R. J Solid State Electrochem. 2012;16:391.

22. El-Dissouky A, El-Bindary AA, El-Soubati AZ, et al. Spectrochim Acta A. 2001;57:1163.

23. Ramos RO, Battistin A, Goncalves RS. J Solid State Electrochem. 2012;16:747.

24. Eddy NO, Odoemelam SA, Mbaba AJ. Afri J Pure Appl Chem. 2008;2:132.

25. Gece G. Corrosion Sci. 2011;53:3873.

26. Kumar SH, Karthikeyan S. Int J Current Research Rev. 2012;4:96.

27. Muralidharan S, Madhavan K, Karthikeyan S, et al. Indian J Chem Technol. 2002;9:68.

28. Bentiss F, Lagrenee M, Traisnel M, et al. Corrosion Sci. 1999;41:789.

29. Ashassi-Sorkhabi H, Shaabani B, Seifzadeh D. Electrochim Acta. 2005;50:344.

30. Karthikeyan S, Neelakandan MA. J Electrochem Soc India. 2006;56:84.

31. Devanathan MAV, Stachurski Z. Proc Roy Soc. 1962;270:90.

32. Shukla SK, Quraishi MA. Corrosion Sci. 2009;51:1990.

33. Madhavan K, Quaraishi MA, Karthikeyan S, et al. J Electrochem Soc India. 2000;49:183.

34. Madhavan K, Karthikeyan S, Venkatakrishna IS. J Electrochem Soc India. 2001;50:37.

35. Eddy NO, Ebenso EE. E-J Chem. 2010;7:S442.

36. Eddy NO, Odoemelam SA, Mbaba AJ. African J Pure Appl Chem. 2008;2:132.

37. Lebrini M, Traisnel M, Lagrenee M, et al. Corrosion Sci. 2008;50:473.

38. Morad MS, Kamal El-Dean AM. Corrosion Sci. 2006;48:3398. 
39. Tang L, Mu G, Liu G. Corrosion Sci. 2003;45:2251.

40. Khamis E, Bellucci F, Latanision RM, et al. Corrosion. 1991;47:677.

41. Geler E, Azambuja DS. Corrosion Sci. 2000;42:631.

42. Abiola OK. Corrosion Sci. 2006;48:3078.

43. Singh AK, Quaraishi MA. Corrosion Sci. 2010;52:1529. 